Revista Complutense de Educación

ISSNe: 1988-2793

http://dx.doi.org/10.5209/RCED.54660

\title{
Francisco Giner de los Ríos y su legado pedagógico
}

Autores: Carmen Colmenar Orzaes, Teresa Rabazas Romero y Sara Ramos Zamora. Editorial: Catarata

Año de publicación: 2015

$N^{a}$ de páginas: 128

ISBN: 978-84-909-7081-2

Decía Américo Castro que de Francisco Giner de los Ríos "no se han escrito gruesos volúmenes, ni en su honor acontecen actos conmemorativos y solemnes". Y es precisamente esta obra, Francisco Giner de los Ríos y su legado pedagógico de las profesoras Carmen Colmenar, Teresa Rabazas y Sara Ramos, de la Universidad Complutense de Madrid, un tributo a su figura. En una obra de fácil y ágil lectura, obtenemos con gran rapidez una visión global de Giner de los Ríos, comenzando por su contexto político, educativo, social y cultural, continuando con su pensamiento y finalizando con su obra más importante: la Institución Libre de Enseñanza.

En una España que se despidió del Antiguo Régimen, Giner de los Ríos vivió en un periodo convulso: en un siglo de sucesivos cambios en el poder, en el seno de un sistema profundamente corrupto e inestable, con varias monarquías, una República, y un aquejado sistema turnista traído por el restauracionismo borbónico. Explicado en un ejercicio de síntesis somero pero correcto, la obra en cuestión se detiene en realizar una contextualización de la educación española de la época, caracterizada por unos altísimos índices de analfabetismo y unas reformas pioneras en nuestro país pero ancladas en los mismos términos. La llegada de Giner irrumpiría en la historia de la educación con renovadores ideales basados en la filosofía krausista y en su oposición a cualquier tipo de doctrina impuesta.

Referido al pensamiento gineriano, una de las principales aportaciones del pedagogo malagueño fue su concepción de la Pedagogía como ciencia, anteponiendo la razón y lo empírico al idealismo y la especulación. Pero sin duda uno de los apartados más enriquecedores de esta lectura, y referido a su pensamiento, es el referido a sus propias propuestas para la mejora del sistema educativo. Cuando se leen las líneas relativas a dicho título, en algunos casos se pierde la noción del tiempo dada la aplicabilidad de las medidas en la actualidad. Su planteamiento se articuló en cuatro grandes ejes que comprendían la renovación del profesorado y su formación pedagógica, la creación de un sistema nacional de educación, el incremento de la financiación en la enseñanza y la libertad de cátedra. Otras de las reformas concretas que planteó fueron las relativas al papel del cuerpo de inspección, el ratio de alumnos por aula, la educación de adultos o la reformulación de la enseñanza secundaria y universitaria, entre otras.

Todas las ideas sostenidas en el segundo capítulo tuvieron su aplicación con la cristalización del proyecto de la Institución Libre de Enseñanza en 1876, a la cual se 
le dedica un extenso tercer capítulo, donde se detallan todas y cada una de las ideas y valores que construyó y desarrolló a lo largo de su historia. El repaso por la ILE supone una exposición pormenorizada de un proyecto de educación alternativa y progresista, y madre a su vez de otras instituciones que consiguieron crear todo un modelo de pedagogía moderna. Basada fundamentalmente en la búsqueda de una educación integral, neutral, libre y única, se basó en planteamientos sobre la figura del maestro, la coeducación, la metodología o el currículo — por citar sólo algunoscompletamente novedosos para la época.

Recientemente, con motivo del centenario de la muerte de Giner en 2015, se han sucedido numerosos homenajes, como el número 471 de Cuadernos de Pedagogía en 2016, donde autores especialistas en este pedagogo como Eugenio Otero Urtaza, Antonio Viñao o María del Mar del Pozo Andrés, entre otros, recogieron varios aspectos de su pensamiento también reseñados en este libro, como la aplicabilidad de sus propuestas a nuestro tiempo o la puesta en valor de la educación pública.

En definitiva, la presente obra se trata de un humilde escrito sobre la vida y obra de Giner de los Ríos, que contribuye a ensalzar su figura y a poner de relieve la necesidad de aplicar pedagogías alternativas en un contexto en el que la educación ha de responder a los rápidos cambios sociales. Un libro que destaca el pensamiento de Giner y de sus proyectos para conseguir una educación de calidad, y que nos permite estudiarle desde sus ideas y no solamente como un rostro utópico del pasado. El objetivo de las autoras parece haber sido no sólo realizar una amplia biografía, sino destacar su carácter aplicado a la educación de hoy. El pensamiento de Giner de los Ríos y la democratización ideológica de la ILE son muy necesarios hoy, y ello debe servir como referente para la búsqueda de un consenso por la educación en España.

La conclusión general tras la lectura es que Giner no era un extranjerizador de España, sino que quería refundarla. Su deseo de mejorar el país pasaba por mejorar la educación, y conseguir de la sociedad española una ciudadanía cívica y formada. En ese momento, y en sus propias palabras, sería "cuando el pueblo español esté por encima de su paisaje".

Carlos Sanz Simón carlossanzsimon@gmail.com Universidad Complutense de Madrid 